\title{
Nationally Determined Contributions (NDCs) under the Paris Agreement and the costs of delayed action
}

Current country-level commitments under the Paris Agreement fall short of putting the world on a required trajectory to stay below a $2^{\circ} \mathrm{C}$ temperature increase compared to pre-industrial levels by the end of the century. Therefore, the timing of increased ambition is hugely important and as such this paper analyses the impact of both the short and long-term goals of the Paris Agreement on global emissions and economic growth. Using the hybrid TIAM-UCL-MSA model we consider the achievement of a $2^{\circ} \mathrm{C}$ target against a baseline of the Nationally Determined Contributions (NDCs) while also considering the timing of increased ambition of the NDCs by 2030 and the impacts of cost reductions of key low-carbon technologies. We find that the rate of emissions reduction ambition required between 2030 and 2050 is almost double when the NDCs are achieved but not ratcheted up until 2030, and leads to lower levels of economic growth throughout the rest of the century. However, if action is taken immediately and is accompanied by increasingly rapid low-carbon technology cost reductions, then there is almost no difference in GDP compared to the path suggested by the current NDC commitments.

Key policy insights

- Delaying the additional action needed to achieve the $2^{\circ} \mathrm{C}$ target until 2030 is shown to require twice the rate of emissions reductions between 2030 and 2050.

- Total cumulative GDP over the century is lower when additional action is delayed to 2030 and therefore has an overall negative impact on the economy, even without including climate change damages.

- Increased ratcheting of the NDC commitments should therefore be undertaken sooner rather than later, starting in conjunction with the 2023 Global Stocktake.

- Early action combined with cost reductions in key renewable energy technologies can reduce GDP losses to minimal levels $(<1 \%)$.

- A $2^{\circ} \mathrm{C}$ future with technological advancements is clearly possible for a similar cost as a $3.3^{\circ} \mathrm{C}$ world without these advances, but with lower damages and losses from climate change. 


\section{Keywords}

Paris Agreement; delayed action; economic impact; NDCs; greenhouse gas emissions; energy system modelling 


\section{Introduction}

The 2015 Paris Agreement, adopted at the $21^{\text {st }}$ Conference of the Parties (COP21) to the United Nations Framework Convention on Climate Change (UNFCCC) is built upon Nationally Determined Contributions (NDCs) ${ }^{\mathrm{i}}$ submitted by countries in the run-up to, and after, COP21. These constitute a starting point from which national policies can be developed to meet the goal of the Paris Agreement, to hold

"the increase in the global average temperature to well below $2^{\circ} \mathrm{C}$ above preindustrial levels" and pursue "efforts to limit the temperature increase to $1.5^{\circ} \mathrm{C}$ " (UNFCCC, 2015a).

The NDCs form part of a more bottom-up paradigm for international climate negotiations, involving voluntary commitments. Previously the negotiation process had been of a more top-down nature with a defined split between the Annex I and Non-Annex I parties - essentially developed and developing nations - accompanied by legally binding targets under the Kyoto Protocol. For the first time, the new process under the Paris Agreement includes voluntary commitments from all major global emitters, both developed and developing, including the US, China and India. However, its long term success will depend on the ambition of NDCs being strengthened in the future, and a verification mechanism providing robust scrutiny.

In this paper, we use a global integrated assessment model (TIAM-UCL-MSA) to consider the NDCs as the baseline and assess the impacts of failure to ratchet up ambition, including the additional effort required to reach the $2^{\circ} \mathrm{C}$ target. We assess what additional mitigation is required beyond the current NDC commitments, by when, and what the economic impacts would be. This is important in the context of the Global Stocktake in 2023 with this paper providing a method of assessment of the timing and costs of such action. 
A range of papers have considered the impact of delayed action, assuming a continuation of the current emission trend out to 2020 or 2030 before re-orientating towards a pathway of $2^{\circ} \mathrm{C}$ after 2030 (Bosetti et al., 2009; Jakob et al., 2012; Keppo \& Rao, 2007; Admiraal et al., 2016; Rogelj et al., 2016; Gambhir et al, 2017; van Soest et al. 2017; Heuberger et al, 2018; Strefler et al. 2018). This change leaves carbon-intensive capital stocks 'stranded' and increases the costs of meeting emissions targets, with losses approximately doubling, in terms of percentage of GDP, compared to taking mitigation action immediately. However, after the Paris Agreement, comparing costs to a situation in which there is essentially no strict climate policy, and therefore little policy-driven decarbonisation is undertaken, is no longer realistic.

It is therefore informative to consider the impact of NDCs in order to update the new policy baseline. A range of papers provide such assessments (Admiraal et al., 2015; Boyd et al, 2015; Ekholm \& Lindroos, 2015; Fawcett et al., 2015; Kitous \& Keramidas, 2015; Rogelj et al., 2016; Spencer \& Pierfederici, 2015; Vandyck et al, 2016; van Soest et al, 2017), the key features of which are summarised in Table 1. These studies entail a range of assumptions concerning the continuation of the ambition shown in the NDCs post-2030, and suggest emission reductions that put the average global temperature increase in the range of 2.7 and $3.7^{\circ} \mathrm{C}$ by 2100 .

Table 1. Summary of NDC assessments reviewed

The majority of studies put GHG emissions in 2030 in the range of $50-56 \mathrm{GtCO}_{2} \mathrm{e}$, which is at similar levels to current emissions of $53.5 \mathrm{GtCO}_{2} \mathrm{e}$ (UNEP, 2018). The ranges produced in the different analyses reflect the conditional and unconditional elements of targets set out in NDCs, with conditional targets (at the low end of the emission range) based on all 
countries meeting their most ambitious targets. ${ }^{\text {ii }}$ UNFCCC (2015b) estimates emissions to be higher, between 53.1 to $58.6 \mathrm{Gt} \mathrm{CO}_{2} \mathrm{e}$. Boyd et al. (2015) has a central range of 52.8 and 56.6

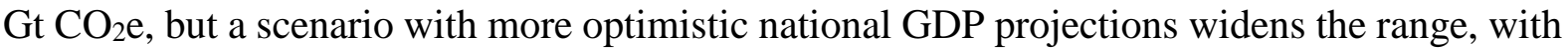
a high estimate of $61 \mathrm{GtCO}_{2} \mathrm{e}$. The recent UNEP (2018) emissions gap report puts 2030

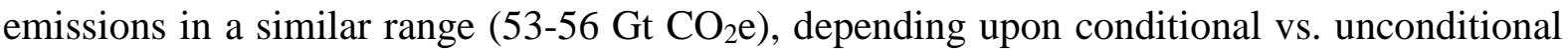
NDCs, resulting in a 2100 temperature increase of $3 \cdot 0-3 \cdot 2^{\circ} \mathrm{C}$. This is against the $2^{\circ} \mathrm{C}$ path of 40

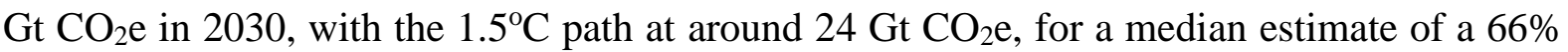
chance of achieving the temperature.

Fawcett et al. (2015) use the GCAM model to assess the impact of the NDCs on temperature goals. The Paris Continued Ambition scenario, where the emissions trajectory reduces at the same rate as during the NDC period, would lead to a $2-3^{\circ} \mathrm{C}$ rise in temperature by the end of the century with a probability around $50 \%$.

Rogelj et al. (2016) find that unconditional NDCs result in around 55 Gt CO2e (52-58 the $10^{\text {th }}$ to $90^{\text {th }}$ percentile range) in 2030 , and $2.4(1.2-4.8)$ Gt CO2e lower under the conditional commitments. Global average temperature increases are estimated at $2.9^{\circ} \mathrm{C}\left(3.2^{\circ} \mathrm{C}\right)$ by 2100 with a $50 \%(66 \%)$ probability for the unconditional NDCs, and $2.7^{\circ} \mathrm{C}\left(3.0^{\circ} \mathrm{C}\right)$ under conditional targets. Van Soest et al. (2017) consider NDCs and delayed action using the IMAGE model framework and project emissions of $50 \mathrm{Gt} \mathrm{CO}_{2} \mathrm{e}$ in 2030.

In addition to estimating the impact of NDCs on the 2030 emissions level, a number of the assessments consider the economic impact. Vandyck et al. (2016) update the earlier POLES analysis (Kitous \& Keramidas, 2015), and use a GEM-E3 global computable equilibrium model to also assess macro-economic impacts. Comparing a NDC and $2^{\circ} \mathrm{C}$ case, with 2030 emissions at 55 and $48 \mathrm{Gt} \mathrm{CO} 2 \mathrm{e}$ respectively, against a reference case (63 Gt CO2e), they estimate global GDP losses in 2030 of around $0.42 \%$ and $0.72 \%$. 
Hof et al. (2017) use the IMAGE model to estimate costs of meeting NDCs, with 2030 emissions estimated at 49.4-54.6 $\mathrm{Gt} \mathrm{CO}_{2} \mathrm{e}$. They estimate abatement costs are three times lower for the conditional NDCs (lower end of the 2030 emission range) than a $2^{\circ} \mathrm{C}$ pathway.

Here we build upon these previous studies and add to the literature in an important way. We focus on the economic implications of a delay in ratcheting up the ambition of the current commitments in terms of GDP change, when compared directly to the NDC pathway (not compared to a current policy or no action scenario, as is often undertaken). The other main study that focuses on GDP change is Vandyck et al. (2016) which does so from a one-way link from a partial equilibrium energy simulation model (JRC-POLES) to a Computable General Equilibrium model (JRC-GEM-E3). Here we add to the debate by providing the results of a hard-linked economic analysis, which includes endogenous demand change in the energy system. We therefore consider how a delay in action until 2030 increases the technological difficulty and cost of achieving the $2^{\circ} \mathrm{C}$ target and therefore evaluate the potential benefits of increasing ambition sooner rather than later. We also consider how falling renewable technology costs may well offset the negative GDP impacts of achieving $2^{\circ} \mathrm{C}$ when compared to previous assumptions.

\section{Methods}

To assess the impacts of delay in ratcheting up NDC ambition to pathways consistent with $2^{\circ} \mathrm{C}$, we use the TIMES Integrated Assessment Model, TIAM-UCL, a global technology-explicit optimisation model which maximises total societal welfare (Bauer, McGlade, Hilaire, \& Ekins, 2018; McGlade \& Ekins, 2015; Price \& Keppo, 2017; Pye et al., 2016). TIAM-UCL models all global primary energy sources across 16 geographical regions, such as coal, oil, gas, nuclear, renewables and biomass, from resource extraction through conversion and finally to their enduse demand in five energy-using sectors: agriculture, transport, industry, households, and 
services. The energy demands are exogenously determined through GDP, population and other drivers. The model is generally run with the assumption of perfect foresight ${ }^{\mathrm{iii}}$ and uses a hardlinked climate module, calibrated to MAGICC, to compute the impact of GHG emissions on global mean surface temperature. Net negative accounting is permitted in the model, while the annual bioenergy resource potential in this analysis is $200 \mathrm{EJ}$ from 2050, which is in line with other integrated assessment models (IAMs) (Bauer et al., 2017; Rogelj et al., 2018). Further information can be found in the model documentation (Anandarajah, Pye, Usher, Kesicki, \& Mcglade, 2011).

This article is the first instance of TIAM-UCL that considers general equilibrium effects, demand responses and potential regional GDP loss for a range of $2^{\circ} \mathrm{C}$ trajectory futures relative to the NDCs. This is achieved by hard-linking TIAM-UCL to a simplified general equilibrium non-linear macroeconomic growth model Macro Stand-Alone (MSA) (Kypreos \& Lehtila, 2013). See Figures A2 and A3 in the Supplementary Information for a brief overview of differences between TIAM-UCL with and without MSA. The benefits of such model linking are discussed in De Carolis et al. (2017)

A number of scenarios have been modelled to explore the impacts of delayed ratcheting up, and are listed in Table 2. The model baseline 'NDC' includes national mitigation commitments to 2030 , followed by no further increase in the level of policy ambition i.e. an assumption of constant GHG emissions per GDP/capita (see Table A2 in Supplementary Information for further details as well as Figures A7 and A8 which explore an alternative baseline assumption). Different $2^{\circ} \mathrm{C}$ target scenarios are then compared against this NDC baseline, varying in terms of both the date from which the targets are pursued, and different assumptions regarding technology diffusion and reductions of costs. For all scenarios, a discount rate of $3.5 \%$ is applied. 


\section{Table 2. TIAM-UCL-MSA scenarios}

In the NDC scenario, the targets of 146 submitted NDCs are included in the scenario, the development of which is further described in the Supplementary Information. Such NDC targets have been aggregated to the regional definitions used in TIAM-UCL-MSA.

Using the climate module, the 2DS scenario requires the modelled temperature increase to be below $2^{\circ} \mathrm{C}$ in 2100 , and remain at this level thereafter. However, overshoot is permitted, meaning that it is possible for the temperature increase to go above $2^{\circ} \mathrm{C}$ and then decline by the end of the century. The range given by Rogelj et al. (2016b) suggests that for a $66 \%$ chance of achieving the $2^{\circ} \mathrm{C}$ budget it should be between 590 and $1,240 \mathrm{Gt} \mathrm{CO}_{2}$ during the period 2015 to 2100 . We check our results against this.

Non- $\mathrm{CO}_{2}$ gases in TIAM-UCL-MSA are modelled exogenously using the assumptions of the representative concentration pathway from the RCP 2.6 scenario (van Vuuren et al., 2011) taken from the IIASA RCP database 2.0. TIAM-UCL-MSA cannot achieve the $1.5^{\circ} \mathrm{C}$ target by 2100 with the standard set of model assumptions i.e. without a backstop technology, and so we do not include a scenario for $1.5^{\circ} \mathrm{C}$ in this analysis. See (Ekins et al. 2017) for a discussion of negative emissions and backstop technology using TIAM-UCL without MSA.

The DA2030 scenario has the same assumptions and targets as the 2DS scenario except that the initial period over which the model is fixed to the NDC baseline is extended by ten years. Therefore the pathway towards the $2^{\circ} \mathrm{C}$ objective only starts from 2030 , with ambition limited to that point to reflect current NDC commitments. ${ }^{\text {iv }}$ A more rapid reduction in emissions is then required than would have been the case had the ratcheting up process started earlier. We have omitted a scenario for 2025 delay as it did not provide any further insight beyond the findings of the van Soest et al (2017) bridge scenario. 
In the 2DS-TECH and DA2030-TECH scenarios, we assume that costs are cheaper for certain key technologies, in particular solar PV and wind (see Supplementary Information for details). These cost reductions are assumed to come about as a result of the increased deployment of these technologies and learning-by-doing. However, these reductions are exogenous and no costs have been included for any policies or $R \& D$ spending that might actually be required. Therefore, there is a delay in investment in these technologies until the costs have reduced. In the baseline, there are also exogenous cost reductions in many nascent technologies, although these tend to be relatively conservative (see Supplementary Information for more details).

\section{Results}

Here we present model outputs, including emission trajectories, the macroeconomic effects of the energy system transition, and the resultant electricity system for the various scenarios listed above.

\section{Emissions}

Our analysis of the effect of the current NDC baseline, plus an assumption of (at a minimum) continued GHG emissions per GDP/capita beyond 2030, suggests that the global temperature increase by the end of the century is around $3.3^{\circ} \mathrm{C}$. For the $2^{\circ} \mathrm{C}$ scenarios, in terms of aggregate GHG reductions between 2030 and 2050, the 2DS scenario entails a reduction rate of $1.6 \%$ a year while DA2030 sees substantially more stringent reductions of $2.6 \%$ per year. These annual average emissions reduction results are roughly in keeping with the UNFCCC (2015b) synthesis report, which concludes that between 2030 and 2050, total GHG emissions are required to reduce at $3.3 \%(2.7-3.9)$ per year when action is only taken beyond the NDC period (i.e. after 2030), and yet when starting from 2010 or 2020, the reduction required is a much lower $1.6 \%(0.6-2.2)$ per year. 
Since TIAM-UCL-MSA has a main focus on energy system-related emissions we provide more detail on $\mathrm{CO}_{2}$ emissions. Our global cumulative carbon budget in each of the $2^{\circ} \mathrm{C}$ emissions reduction scenario falls between $910-930 \mathrm{Gt} \mathrm{CO}_{2}$ which is within the range stated in Rogelj et al. (2016b). Global $\mathrm{CO}_{2}$ emissions to 2080 are shown in Figure 1 for the various scenarios. These results provide an indication of the necessary level and rate of emission reduction depending on the delay in moving to a $2{ }^{\circ} \mathrm{C}$ pathway. Global $\mathrm{CO}_{2}$ emissions in the NDC baseline are 36.7 Gt in 2030, growing 6\% overall from 2010 levels in TIAM-UCL-MSA. However, between 2020 and 2030 in the 2DS and 2DS-TECH scenarios (where mitigation is ratcheted up in 2020), $\mathrm{CO}_{2}$ emissions need to reduce at a rate of $4.1 \%$ and $3.9 \%$ per year, respectively.

Figure 1. Global $\mathrm{CO}_{2}$ emissions to $2080(\mathrm{Gt})$

In terms of delayed action, in the DA2030 scenario, global net $\mathrm{CO}_{2}$ emissions are required to fall at around $6.1 \%$ per year between 2030 and 2050, while the reduction rate is only $3.5 \%$ per year in the 2DS scenario, showing that almost twice the extra effort is required annually if action is delayed by 10 years. Both delayed scenarios require global net negative $\mathrm{CO}_{2}$ emissions by 2065 while the non-delay scenarios require net-negative emissions about five years later in 2070. These are all consistent with the necessity for net zero-carbon in the second half of the century, and eventually net $\mathrm{CO}_{2}$ removal from the atmosphere.

\section{Economy}

The percentage change in the global GDP level for each of the scenarios compared against the NDC baseline is shown in Figure 2 (a). The most significant GDP loss occurs for the DA2030 scenario as, although delaying action is beneficial in the short-term, by the middle of the century total GDP is 5\% lower than the NDC level. The large losses from DA2030 show the higher negative impacts from a longer delay, and that ratcheting up NDC ambition is beneficial 
in reducing losses. Interestingly, the 2DS-TECH scenario reaches a level of GDP in 2045 less than $1 \%$ lower than the NDC baseline and continues to stay above that level thereafter, showing the important role that technological development and falling costs of renewables can play in achieving long-term targets at minimal cost. Support from policymakers to continue reducing technology costs can therefore have significant effects in removing cost barriers to action, therefore speeding up mitigation while minimizing or removing impacts on economic growth. A $2{ }^{\circ} \mathrm{C}$ future with technological advancements is clearly possible for a similar cost as a $3.3^{\circ} \mathrm{C}$ world without these advances, but with lower damages and losses from climate change (which are not modelled here). For instance, the cumulative GDP of 2DS-TECH is only $0.5 \%$ lower than the cumulative GDP of NDC baseline, whereas the 2DS scenario is $5.3 \%$ lower overall. Even in the delayed scenarios there is a significant level of GDP loss offset through lower technology costs as DA2030-TECH has $2 \%$ lower GDP cumulatively over the model horizon.

Figure 2. (a) Global GDP \% change compared against NDC, (b) GDP level, (c) Annual global GDP growth rate

These results show that there are some reductions in rates of economic growth due to mitigation in all scenarios before 2050. In particular, delaying action makes the economy worse off compared to non-delay scenarios over the entire model period, as shown in Figure 2 (b) and (c), which give the global GDP levels and growth rates, respectively, for each of the scenarios over the 2015-2080 timeframe. Crucially, there is still strong economic growth in all the scenarios over the whole model period when achieving $2^{\circ} \mathrm{C}$, although the results will differ by region (see Figure 3, Figure A5 and Figure A6 for regional differences). Between 2030 and 2035, global GDP growth in the NDC baseline is still above 3\% a year as is 2DS-TECH, albeit slightly lower. However, all other scenarios have a growth rate slightly below 3\%. In 2050, 
GDP in the best instance (2DS-TECH) grows at 2.8\%, faster than the NDC baseline at $2.7 \%$ per annum while the slowest growth, at $2.5 \%$, is in the DA2030 case.

In fact, between 2045 and 2060 the 2DS-TECH scenario has a higher GDP growth rate than the NDC case, showing that fast-reducing technology costs could help achieve the necessary emissions reductions while roughly providing no net change to the global economy over the timeframe of the analysis. The GDP growth rate in the DA2030-TECH case becomes higher from 2050 onwards and broadly matches the NDC growth rate thereafter.

Overall, the discounted energy system costs are lower in DA2030 than in 2DS by about $0.4 \%$, although a lower discount rate would change this dynamic somewhat (Admiraal et al. 2016). However, the lower mitigation costs are due to a smaller energy system as final energy consumption is lower than in 2DS throughout the century after 2035. Therefore, total cumulative GDP is also lower overall, by $1.3 \%$, in DA2030 than in 2DS showing that delay has an overall negative impact on the economy. This validates the iterative approach of using a framework where endogenous demand and GDP change are included. Figure 3 compares the regional GDP losses of DA2030 against those of 2DS. Unsurprisingly, the majority of regions are better off before 2030 under the DA2030. However, thereafter, the level of mitigation required increases significantly the negative economic impacts of mitigation. Large fossil fuel consumers and producers such as China, the Former Soviet Union region, and the Middle East all have losses of around 8\% of GDP in 2050 and these grow in 2070 to $10 \%$ for China and $12 \%$ for the Former Soviet Union region. Further regional economic comparisons are presented in the Supplementary Information.

Figure 3. Regional GDP change in DA2030 against 2DS 


\section{Electricity generation}

Given the importance of the power generation technology assumptions in reducing negative GDP impacts, we show in more detail here the implications of these assumptions on the electricity system. The assumptions are discussed in greater detail in the Supplementary Information. The overall level of electricity generation grows between each period due to model assumptions about rising energy service demands driven by economic growth and population; however, these differ by scenario (see Figure 4).

The NDC baseline has a higher level of total electricity generation in 2030 than 2DS or 2DS-TECH. The main difference in electricity mix between the scenarios in 2030 is that unabated coal generation contributes to $29 \%$ of generation in the NDC baseline but only $6 \%$ and $7 \%$ in 2DS and 2DS-TECH, although gas plays a similar role in all instances. In the NDC baseline, by 2030 there is little penetration of wind and solar globally, with about $6.5 \%$ of generation combined, whereas these are $12 \%$ and $17 \%$ of generation in the 2DS and 2DSTECH scenarios. ${ }^{\mathrm{v}}$

Figure 4. Electricity generation (EJ) in 2030, 2050 and 2080

However, by 2050 and 2080, the overall levels of electricity generation increase more in the $2^{\circ} \mathrm{C}$ scenarios because greater levels of electrification are required throughout the energy system, and particularly so in the transport sector, to achieve the decarbonisation objective.

In 2050 solar provides about 9\% of generation in the NDC baseline. For 2DS and 2DSTECH solar power contributes $17 \%$ and $26 \%$ of total electricity generation. Wind technologies also play a more significant role by 2050 accounting for $10 \%$ and $15 \%$ in in 2DS and 2DSTECH, respectively. 
In the long-run, by 2080 global electricity production doubles again for the $2^{\circ} \mathrm{C}$ scenarios compared to 2050. In both 2DS and 2DS-TECH, solar technologies play a significant role in electricity generation, amounting to $33 \%$ and $38 \%$, respectively.

\section{Discussion}

This study assumes that the NDC commitments are the baseline to which any near-term action (or non-action) and the longer term Paris goals should be compared. However, there is considerable uncertainty around any assumptions. Our analysis suggests that continued ambition at the same level as the current NDCs would lead to a global average temperature increase by 2100 of close to $3.3^{\circ} \mathrm{C}$, over double the $1.5^{\circ} \mathrm{C}$ aspiration of the Paris Agreement.

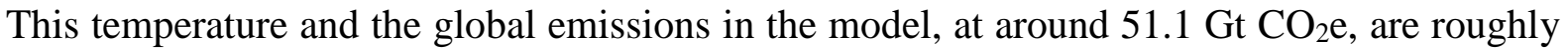
in line with other estimates of the NDCs in 2030. (van Soest et al. 2017; Rogelj et al. 2016; Hof et al. 2017). However, in the Supplementary Information, we provide comparison to an alternative baseline (NDC-ALT), where more emissions reduction action is taken by regions post-2030 leading to a temperature change of $3.1^{\circ} \mathrm{C}$ in 2100 , and we provide details of how this different assumption affects the results for $\mathrm{CO}_{2}$ emissions and GDP in Figures $\mathrm{A} 7$ and $\mathrm{A} 8$, respectively.

Large uncertainties exist around the costs of delaying action. Admiraal et al. (2016) do not consider endogenous GDP effects but do find that the annual mitigation costs are around 1-2\% of global GDP. Van Soest et al. (2017) also find higher cumulative abatement costs of $18 \%$ over the period 2010-2100 when action is delayed until 2030 instead of 2020, however there is no endogenous demand change here. An interesting alternative approach, in further analysis, may be to explore the implications of delay through a more explorative approach, including temperature goal exceedance. 
Reductions in assumed future technology costs make a significant difference to the macro-economic impacts of achieving the $2^{\circ} \mathrm{C}$ temperature target in the Paris Agreement. In particular, we find in this accelerated technology instance that achieving a $2^{\circ} \mathrm{C}$ target incurs a less than one percent difference $(<1 \%)$ in global GDP in the second half of the century compared to the NDC scenario, where renewables costs do not change.

The electricity system is still carbon intensive in the NDC case and dependent upon coal and gas during the period up to 2030. Therefore, if the NDC goals are not ratcheted up until 2030, then meeting the $2^{\circ} \mathrm{C}$ target will require a net $\mathrm{CO}_{2}(\mathrm{GHG})$ mitigation rate between 2030 and 2050 of $6.1 \%(2.6 \%)$ a year. Van Soest et al. (2017) see reductions of $6.4 \%(4.7 \%)$ over this period, with larger reduction rates in overall GHGs. This is potentially because of differing technological assumptions and also the ability of their modelling approach to capture non- $\mathrm{CO}_{2}$ GHGs and land use change and forestry sector emissions reductions in a comprehensive manner. Earlier action from 2020 onwards would require a lower, yet still substantial, yearly rate of reduction of $3.5 \%(1.6 \%)$. Based on historical estimates these may be more plausible as Riahi et al. (2013) find that sustained reductions in $\mathrm{CO}_{2}$ emissions have occurred in some regions in the past - although most of these were during recessions. However, history may not be the best predictor of rates of change for future emissions as the substitutability of low-carbon technologies, at scale, is a relatively new phenomenon. Therefore, attention to sensitivity of low-carbon costs and their ability to penetrate and integrate into the energy system is needed (See Supplementary Information for more on renewable cost uncertainty). In terms of fossil fuel electricity generation, it is unlikely in reality we will encounter the types of large reductions in coal generation by 2030 as in the various modelled scenarios to achieve the Paris Agreement goals, and this finding suggests that delay is perhaps even more problematic. 
In reality, the lack of availability of other technologies not yet at scale e.g. Bioenergy with carbon capture and storage (BECCS), electric vehicles (EVs), industrial CCS etc., in a meaningful time frame may well make the achievement of continued rates of reduction throughout the century a challenge. In addition, without such negative emission technologies, it is likely that demand change and behavioural aspects will become even more significant in our ability to achieve long-term climate goals, and these must be better incorporated into analyses (van Vuuren et al, 2018; Grubler et al, 2018). We do not incorporate behaviour change or societal preferences in our modelling work here and therefore further exploration of sensitivities around energy demands is required in future. There are other real-world aspects, not captured here, which may affect the ability to achieve the modelled transitions. For instance, our modelling approach does not consider effects of policy and decision-making (Nerini, et al. 2017; Heuberger et al. 2018) which can add to lock-in and inertia in the system and higher costs. On the other hand, our analysis does not include climate damages and as such we only consider an assessment of the mitigation costs which may be offset, partially or wholly, later in the second half of the century, as in Admiraal et al (2016) where the discount rate applied determines whether delayed action has net benefits (avoided damages minus mitigation cost). Literature suggests early, stringent mitigation can help avoid significant parts of the climate impacts in the second half of the century (Warren et al, 2013; Moore and Diaz, 2015). This analysis would be strengthened if we were able to compare the $0.5 \%$ cumulative GDP loss of 2DS-TECH against the cumulative climate damages of a $3.3^{\circ} \mathrm{C}$ world. Future work will consider including aspects of climate damages, an exploration of demand change, and consideration of myopic decision-making into our global modelling framework, alongside their implications on computational resource. 


\section{Conclusions}

Our analysis provides a modelling assessment of meeting the NDCs and the Paris Agreement's $2^{\circ} \mathrm{C}$ target. Our modelling of the current NDC ambition leads to a $3.3^{\circ} \mathrm{C}$ temperature increase by the end of the century. We use this as a baseline to compare the necessary action to reach $2^{\circ} \mathrm{C}$ while considering the impacts of delayed action and accelerated technology impacts on the energy system and the economy. Rates of emissions reductions are significantly higher when ratcheting up action is delayed by ten years until 2030. In this instance, global net $\mathrm{CO}_{2}$ emissions are required to fall around double the annual rate between 2030 and 2050 as would otherwise be the case to achieve $2^{\circ} \mathrm{C}$.

Immediate action from 2020 to achieve the $2^{\circ} \mathrm{C}$ target results in a strong global economic growth rate in 2050 of $2.6 \%$, compared to $2.7 \%$ in the NDC baseline, which equates to a total global GDP level in 2050 that is around 4\% lower than under the NDC baseline. Thus strong climate ambition is shown under these circumstances to be fully consistent with robust, sustained global economic growth, although the economic impacts differ significantly by region.

Delaying increased action until 2030 in our analysis sees the rate of global economic growth slow beyond 2030, resulting in a global GDP that is $1.6 \%$ lower in 2050 than the optimal $2^{\circ} \mathrm{C}$ pathway from 2020 , and $5.6 \%$ lower than the NDC baseline. Beyond 2050, these negative impacts continue and the difference in economic costs between 2DS and DA2030 increases over time. Cumulative global GDP is lowest overall when action is delayed; therefore, taking stronger action now is vitally important to reduce the costs of meeting the Paris targets.

Importantly, however, a key conclusion from our analysis is that robust mitigation ambition towards the $2^{\circ} \mathrm{C}$ target starting now, combined with accelerated low-carbon technological innovation, can both mitigate climate change as envisaged in the Paris 
Agreement, and achieve strong long-term global economic growth rates, but with lower damages from increased global temperatures.

\section{References}

Admiraal, A., den Elzen, M., Forsell, N., Turkovska, O., Roelfsema, M., \& van Soest, H. (2015). Assessing Intended Nationally Determined Contributions to the Paris climate agreement-what are the projected global and national emission levels for 2025-2030. Bilthoven, Netherlands: PBL Netherlands Environmental Assessment Agency.

Admiraal, A. K., A. F. Hof, M. G. J. den Elzen and D. P. van Vuuren (2016). "Costs and benefits of differences in the timing of greenhouse gas emission reductions." Mitigation and Adaptation Strategies for Global Change, 21(8): 1165-1179.

Anandarajah, G., Pye, S., Usher, W., Kesicki, F., \& Mcglade, C. (2011). TIAM-UCL Global model documentation. UCL. Retrieved from http://www.ucl.ac.uk/energymodels/models/tiam-ucl/

Bauer, N., Calvin, K., Emmerling, J., Fricko, O., Fujimori, S., Hilaire, J., Eom, J., Krey, V., Kriegler, E., Mouratiadou, I., de Boer, H. S., van der Berg, M., Carrara, S., Daioglou, V., Drouet, L., Edmonds, J. E., Gernaat, D., Havlik, P., Johnson, N., Klien, D., Kyle, P., Marangoni, G., Masui, T., Pietzcker, R. C., Strubegger, M., Wise, M., Riahi, K. \& van Vuuren, D. P. (2017). Shared Socio-Economic Pathways of the Energy Sector Quantifying the Narratives. Global Environmental Change, 42, 316-330. https://doi.org/10.1016/j.gloenvcha.2016.07.006

Bauer, N., McGlade, C., Hilaire, J., \& Ekins, P. (2018). Divestment prevails over the green paradox when anticipating strong future climate policies. Nature Climate Change, $8(2)$, 130-134. https://doi.org/10.1038/s41558-017-0053-1 
Bosetti, V., Carraro, C., Sgobbi, A., \& Tavoni, M. (2009). Delayed action and uncertain stabilisation targets. How much will the delay cost? Climatic Change, 96(3), 299-312. https://doi.org/10.1007/s10584-009-9630-2

Boyd, R., Cranston Turner, J., \& Ward, B. (2015). Tracking intended nationally determined contributions: what are the implications for greenhouse gas emissions in 2030?. ESRC Centre for Climate Change Economics and Policy (CCCEP) and the Grantham Research Institute on Climate Change and the Environment.

DeCarolis, J., Daly, H., Dodds, P., Keppo, I., Li, F., McDowall, W., Pye, S., Strachan, N., Trutnevyte, E., Usher, W., Winning, M., Yeh, S., \& Zeyringer, M. (2017). Formalizing best practice for energy system optimization modelling. Applied Energy, 194, 184-198. http://doi.org/10.1016/j.apenergy.2017.03.001

Ekholm, T., \& Lindroos, T. J. (2015). An Analysis of Countries' Climate Change Mitigation Contributions Towards the Paris Agreement. White Paper, VTT Technical Research Centre of Finland Ltd.

Ekins, P., Hughes, N. Pye, P. Winning, M. Macrory, R. Milligan, B. Hazeldine, S. Watson, J. (2017). The role of CCS in meeting climate policy targets. Report for the Global CCS Institute, available at http://hub.globalccsinstitute.com/sites/default/files/publications/201833/report-role-ccsmeeting-climate.pdf

Fawcett, A. A., Iyer, G. C., Clarke, L. E., Edmonds, J. A., Hultman, N. E., McJeon, H. C., Rogelj, J., Schuler, R., Alsalam, J., Asrar, G. R., Creason, J., Jeong, M., McFarland, J., Mundra, A., Shi, W. (2015). Can Paris pledges avert severe climate change? Science. https://doi.org/10.1126/science.aad5761

Gambhir,A., Drouet, L., McCollum, D., Napp, T., Bernie, D., Hawkes, A., Fricko, O., Havlik, P., Riahi, K., Bosetti, V., Lowe, J. (2017), Assessing the Feasibility of Global Long-Term Mitigation Scenarios, Energies, 2017, 10, 89, doi:10.3390/en10010089 
Grubler, A., Wilson, C., Bento, N., Boza-Kiss, B., Krey, V., McCollum, D. L., Rao, N. D., Riahi, K., Rogelj, J., De Stercke, S., Cullen, J., Frank, S., Fricko, O., Guo, F., Gidden, M., Havlik, P., Huppmann, D., Kiesewetter, G., Rafaj, P., Schoepp, W. \& Valin, H. (2018). A low energy demand scenario for meeting the $1.5 \mathrm{C}$ target and sustainable development goals without negative emission technologies. Nature Energy, 3(6), 515.

Heuberger, C. F., Staffell, I., Shah, N., MacDowell, N. (2018) Impact of myopic decision making and disruptive events in power systems planning, Nature Energy, Vol. 3, August 2018, 634-640, https://doi.org/10.1038/s41560-018-0159-3

Hof, A. F., den Elzen, M. G. J., Admiraal, A., Roelfsema, M., Gernaat, D. E. H. J., \& van Vuuren, D. P. (2017). Global and regional abatement costs of Nationally Determined Contributions (NDCs) and of enhanced action to levels well below $2{ }^{\circ} \mathrm{C}$ and $1.5^{\circ} \mathrm{C}$. Environmental Science and Policy, 71, 30-40. https://doi.org/10.1016/j.envsci.2017.02.008

IRENA (2018) Renewable Power Generation Costs in 2017, International Renewable Energy Agency, Abu Dhabi

Jakob, M., Luderer, G., Steckel, J., Tavoni, M., \& Monjon, S. (2012). Time to act now? Assessing the costs of delaying climate measures and benefits of early action. Climatic Change, 114(1), 79-99. https://doi.org/10.1007/s10584-011-0128-3

Keppo, I., \& Rao, S. (2007). International climate regimes: Effects of delayed participation. Technological Forecasting and Social Change, 74(7), 962-979. https://doi.org/10.1016/j.techfore.2006.05.025

Kitous, A., \& Keramidas, K. (2015). Analysis of scenarios integrating the INDCs - JRC POLICY BRIEF. JRC POLICY BRIEF Analysis. Retrieved from https://ec.europa.eu/jrc/en/news/current-climate-commitments-would-increase-globaltemperature-around-3-degrees 
Kypreos, S., \& Lehtila, A. (2013). TIMES-MACRO: decomposition into hard-linked LP and NLP problems. ETSAP TIMES 3.4 User Note.

McGlade, C., \& Ekins, P. (2015). The geographical distribution of fossil fuels unused when limiting global warming to $2{ }^{\circ} \mathrm{C}$. Nature, 517(7533), 187-190. https://doi.org/10.1038/nature14016

Moore, F. C. and Diaz, D. B. (2015), Temperature impacts on economic growth warrant stringent mitigation policy, Nature Climate Change, Vol 5, February 2015

Nerini, F., Keppo, I., Strachan, N. (2017). Myopic decision making in energy system decarbonisation pathways. A UK case study. Energy Strategy Reviews, 17, 19-25. http://dx.doi.org/10.1016/j.esr.2017.06.001

Price, J., \& Keppo, I. (2017). Modelling to generate alternatives: A technique to explore uncertainty in energy-environment-economy models. Applied Energy, 195, 356-369. https://doi.org/10.1016/j.apenergy.2017.03.065

Pye, S., McGlade, C., Bataille, C., Anandarajah, G., Denis-Ryan, A., \& Potashnikov, V. (2016). Exploring national decarbonization pathways and global energy trade flows: a multi-scale analysis. Climate Policy, 16(sup1), 1-18. https://doi.org/10.1080/14693062.2016.1179619

Riahi, K., Kriegler, E., Johnson, N., Bertram, C., Elzen, M. Den, Eom, J., Schaffer, M., Edmonds, J., Isaac, M., Krey, V., Longden, T., Luderer, G., Mejean, A., McCollum, D. L., Mima, S., Turton, H., van Vuuren, D. P., Wada, K., Bosetti, V., Capros, P., Criqui, P., Hamdi-Cherif, M., Kainuma, M., Edenhofer, O. (2015). Technological Forecasting \& Social Change Locked into Copenhagen pledges - Implications of short-term emission targets for the cost and feasibility of long-term climate goals. Technological Forecasting \& Social Change, 90, 8-23. https://doi.org/10.1016/j.techfore.2013.09.016 Rogelj, J., den Elzen, M., Höhne, N., Fransen, T., Fekete, H., Winkler, H., Schaeffer, R., Sha, 
F., Riahi, K., Meinshausen, M. (2016). Paris Agreement climate proposals need a boost to keep warming well below $2{ }^{\circ} \mathrm{C}$. Nature, 534(7609), 631-639.

https://doi.org/10.1038/nature18307

Rogelj, J., Popp, A., Calvin, K. V, Luderer, G., Emmerling, J., Gernaat, D., Fujimori, S., Strefler, J., Hasegawa, T., Marangoni, G., Krey, V., Kriegler, E., Riahi, K., van Vuuren, D.P., Doelman, J., Drouet, L., Edmonds, J., Fricko, O., Harmsen, M., Hvlik, P., Humpenoder, F., Stehfest, E., \& Tavoni, M. (2018). Scenarios towards limiting global mean temperature increase below $1.5^{\circ} \mathrm{C}$. Nature Climate Change. https://doi.org/10.1038/s41558-018-0091-3

Rogelj, J., Schaeffer, M., Friedlingstein, P., Gillett, N. P., van Vuuren, D. P., Riahi, K., Allen, M., \& Knutti, R. (2016b). Differences between carbon budget estimates unravelled. Nature Climate Change, 6(3), 245-252.

Spencer, T., \& Pierfederici, R. (2015). Beyond the numbers: Understanding the transformation induced by INDCs. Beyond the Numbers: Understanding the Transformation Induced by INDCs. A Report of the MILES Project Consortium, (October), 80. Retrieved from http://www.iddri.org/Publications/Beyond-the-numbersUnderstanding-the-transformation-induced-by-INDCs

Strefler, J., N. Bauer, E. Kriegler, A. Popp, A. Giannousakis \& O. Edenhofer (2018). "Between Scylla and Charybdis: Delayed mitigation narrows the passage between largescale CDR and high costs." Environmental Research Letters, 13(4).

UNFCCC (2015a). Adoption of the Paris Agreement. Conference of the Parties on Its Twenty-First Session, 21932(December), 32. https://doi.org/FCCC/CP/2015/L.9 UNFCCC (2015b) Synthesis Report on the Aggregate Effect of the Intended Nationally Determined Contributions [online], FCCC/CP/2015/7, 30 October. Available from: http://unfccc.int/resource/docs/2015/cop21/eng/07.pdf accessed 25th September 2018 
UNEP (2018). The Emissions Gap Report 2018. United Nations Environment Programme, Nairobi

Van Soest, H. L., H. S. de Boer, M. Roelfsema, M. G. J. den Elzen, A. Admiraal, D. P. van Vuuren, A. F. Hof, M. van den Berg, M. J. H. M. Harmsen, D. E. H. J. Gernaat and N. Forsell (2017). "Early action on Paris Agreement allows for more time to change energy systems." Climatic Change, 144(2): 165-179.

Van Vuuren, D. P., Edmonds, J., Kainuma, M., Riahi, K., Thomson, A., Hibbard, K., Hurtt, G. C., Kram, T., Krey, V., Lamarque, JF, Masui, T., Meinhausen, M., Nakicenovic, N., Smith, S. J., Rose, S. K. (2011). The representative concentration pathways: An overview. Climatic Change, 109(1), 5-31. https://doi.org/10.1007/s10584-011-0148-z

Van Vuuren, D. P., Stehfest, E., Gernaat, D. E., Berg, M., Bijl, D. L., Boer, H. S., Daioglou, V., Doelman, J. C., Edelenbosch, O. Y., Harmsen, M., Hof, A. F., \& van Sluisveld, M. A. E. (2018). Alternative pathways to the $1.5 \mathrm{C}$ target reduce the need for negative emission technologies. Nature Climate Change, 8(5), 391-397.

Vandyck, T., Keramidas, K., Saveyn, B., Kitous, A., \& Vrontisi, Z. (2016). A global stocktake of the Paris pledges: implications for energy systems and economy. Global Environmental Change, 41, 46-63.

Warren, R., Lowe, J. A., Arnell, N. W., Hope, C., Berry, P., Brown, S., Gambhir, A., Gosling, S.N., Nicholls, R. J., O'Hanley, J., Osborn, T. J., Osborne, T., Price, J., Raper, S. C.B., Rose, G., Vanderwal, J. (2013). The AVOID programme's new simulations of the global benefits of stringent climate change mitigation, Climatic Change, 55-70. https://doi.org/10.1007/s10584013-0814-4 
${ }^{\text {i }}$ Previously these were Intended Nationally Determined Contributions (INDCs). The INDCs are now referred to simply as NDCs for those countries that have ratified the Paris Agreement. The terms can be considered interchangeably in this paper.

ii An unconditional NDC refers to a voluntary commitment made by a party that will be undertaken regardless of the action of any other party or any financial support provided. A conditional NDC refers to commitments made by a party which are dependent upon the action of other parties in order for them to take stronger action e.g. financial support or an action by another party. A single party may provide both a conditional and unconditional NDC. For instance, Nigeria has a $20 \%$ unconditional target and a $45 \%$ conditional target set against baseline emissions in 2030.

iii There are limitations of employing perfect foresight in the analysis as in practice decisions are often made in a myopic manner over shorter time-frames which can result in considerably higher costs (Nerini et al, 2017; Heuberger et al, 2018).

${ }^{\text {iv }}$ As the scenario results for DA2030 are fixed to the NDC baseline until 2030 this can be considered similar to a myopic instance where decisions can only be taken post-2030

${ }^{v}$ Obviously these are model scenarios and may not represent reality, such as the impacts of cheaper renewables where cost reductions are moving faster than expected (IRENA (2018)). 